\title{
Solar cells using bulk crystals of rare metal-free compound semiconductor ZnSnP
}

\section{$\operatorname{AUTHOR}(\mathrm{S})$ :}

Nakatsuka, Shigeru; Yuzawa, Noriyuki; Chantana, Jakapan; Minemoto, Takashi; Nose, Yoshitaro

\section{CITATION:}

Nakatsuka, Shigeru ...[et al]. Solar cells using bulk crystals of rare metal-free compound semiconductor ZnSnP. physica status solidi (a) 2017,214(2): 1600650

\section{ISSUE DATE:}

2017-02

URL:

http://hdl.handle.net/2433/243845

\section{RIGHT:}

This is the peer reviewed version of the following article: Nakatsuka, S., Yuzawa, N. Chantana, J., Minemoto, T. and Nose, Y. (2017), Solar cells using bulk crystals of rare metal - free compound semiconductor ZnSnP2. Phys. Status Solidi A, 214: 1600650., which has been published in final form at https://doi.org/10.1002/pssa.201600650. This article may be used for non-commercial purposes in accordance with Wiley Terms and Conditions for Use of Self-Archived Versions.; この論文は出版社版でありません。引用の際には出版社版をご確認ご利用ください。;This is not the published version. Please cite only the published version. 


\section{Solar cells using bulk crystals of rare metal - free compound}

\section{semiconductor $\mathrm{ZnSnP}_{2}$}

Shigeru Nakatsuka ${ }^{1}$, Noriyuki Yuzawa ${ }^{2}$, Jakapan Chantana ${ }^{2}$,

Takashi Minemoto ${ }^{2}$ and Yoshitaro Nose $\mathrm{N}^{1 \mathrm{a}}$

${ }^{1}$ Department of Materials Science and Engineering, Kyoto University, 606-8501,

Yoshida-Honmachi, Sakyo-ku, Kyoto, Japan.

${ }^{2}$ College of Science and Engineering, Ritsumeikan University, 525-8577, Nojihigashi

Kusatsu, Shiga, Japan.

Keyword; $\mathrm{ZnSnP}_{2}$, chalcopyrite, solar cells, rare metal free

Author to whom all correspondence should be addressed. Tel.: +81-75-753-5472; Fax: +81-75-753-3579;

a) E-mail: nose.yoshitaro.5e @kyoto-u.ac.jp. 


\section{Abstract}

We report on the performance of solar cells using $\mathrm{ZnSnP}_{2}$ compound semiconductor

consisting of safe and earth-abundant elements for the first time. The minority carrier lifetimes in bulk crystals of $\mathrm{ZnSnP}_{2}$ were 0.44 and $14 \mathrm{~ns}$, which were obtained by analysis using double exponential function in time-resolved photoluminescence. The lifetime is close to that of CIGS, which is as high as to achieve the conversion efficiency of over $16 \%$. The structure of an $\mathrm{Al} / \mathrm{Al}$-doped $\mathrm{ZnO} / \mathrm{ZnO} / \mathrm{CdS} / \mathrm{ZnSnP} / \mathrm{Mo}$ was adopted for the fabrication of solar cells. The short-circuit current density and the open circuit voltage are $2 \mathrm{~mA} / \mathrm{cm}^{2}$ and $0.17 \mathrm{~V}$, respectively. The wavelength at the absorption edge in external quantum efficiency is consistent with the bandgap of $\mathrm{ZnSnP}_{2}$. However, the conversion efficiency is approximately $0.09 \%$, and higher performance is required. The current density-voltage curve suggests that the reduction of series resistance is needed because it is higher than the value expected from the resistivity of bulk $\mathrm{ZnSnP}_{2}$. The improvement of conduction band offset is also necessary considering from our previous works. 


\section{Introduction}

Solar cells using compound semiconductors have made huge progress in recent years.

In particular, the solar cells based on $\mathrm{CuIn}_{1-x} \mathrm{Ga}_{x} \mathrm{Se}_{2}$ (CIGS) and CdTe have achieved high

conversion efficiencies of $22.3^{[1]}$ and $22.1 \%,{ }^{[2]}$ respectively. However, the use of rare or toxic elements suppresses the widespread use of these materials. From these backgrounds,

solar absorbing materials composed of earth-abundant and safe elements have been investigated and $\mathrm{Cu}_{2} \mathrm{ZnSnS}_{4-x} \mathrm{Se}_{x}$ solar cells have been developed with a conversion efficiency of $12.6 \%{ }^{[3]}$ The other compounds, such as $\mathrm{Cu}_{2} \mathrm{SnS}_{3},{ }^{[4]} \mathrm{Cu}_{2} \mathrm{O},{ }^{[5]} \mathrm{SnS},{ }^{[6]} \mathrm{Fe}_{2} \mathrm{~S}{ }^{[7]}$ and $\mathrm{Zn}_{3} \mathrm{P}_{2}{ }^{[8]}$ have been also researched for the same purpose.

$\mathrm{ZnSnP}_{2}$ has been proposed as a promising candidate for a solar absorbing material consisting of earth-abundant and safe elements. In the previous works, it was reported that $\mathrm{ZnSnP}_{2}$ with a chalcopyrite structure showed a p-type conduction with the carrier concentration in a range of $10^{16}-10^{18} \mathrm{~cm}^{-3}[9-16]$ and has a direct bandgap of $1.6-1.7$ eV. ${ }^{[14-17]}$ According to Shockley-Queisser theory, ${ }^{[18]}$ the conversion efficiency of over $30 \%$ is calculated in single-junction cells with $\mathrm{ZnSnP}_{2}$ absorber under an $\mathrm{AM} 1.5 \mathrm{G}$ solar 
spectrum. ${ }^{[19]}$ In addition, the absorption coefficient of $\mathrm{ZnSnP}_{2}$ is about $10^{5} \mathrm{~cm}^{-1}$ in the visible light region $^{[19,20]}$, which is close to that of CIGS. ${ }^{[19,21]}$

As mentioned above, $\mathrm{ZnSnP}_{2}$ is suitable as an absorber material from the viewpoints of electrical and optical properties, however, solar cells based on $\mathrm{ZnSnP}_{2}$ have not been reported yet. In our group, the bulk crystals of $\mathrm{ZnSnP}_{2}$ with the diameter of $\sim 8 \mathrm{~mm}$ were prepared by solution growth with the slow cooling rate of $\sim 0.7^{\circ} \mathrm{C} / \mathrm{h} .{ }^{[16]}$ The obtained crystals demonstrated the p-type characteristic with the hole density of $10^{16}-10^{18} \mathrm{~cm}^{-3}$, which was measured by van der Pauw method. ${ }^{[16]}$ The size of our crystals is larger than the reported $\mathrm{ZnSnP}_{2}$ crystals with the dimension of $\sim 4 \times 4 \mathrm{~mm}^{2}$ and the thickness of $\sim 0.5$ $\mathrm{mm}$, which were obtained by the rapid cooling rate of $10 \sim 50{ }^{\circ} \mathrm{C} / \mathrm{h} \cdot{ }^{[10,11,13,14]}$ Accordingly, our crystals with relatively large diameter was utilized for the fabrication of solar cells. We here report on photovoltaic performance of solar cells using $\mathrm{ZnSnP}_{2}$ bulk crystals as a solar absorber for the first time. 


\section{Experimental methods}

$\mathrm{ZnSnP}_{2}$ bulk crystals were prepared by flux method, a kind of solution growth, reported in our previous work. ${ }^{[16]}$ For the crystal growth, raw materials, Zn shots $(99.99 \%$, Kojundo Chemical Laboratory), Sn shots (99.99 \%, Kojundo Chemical Laboratory) and red phosphorus flacks (99.9999 \%, Kojundo Chemical Laboratory) were sealed in an evacuated quartz ampoule below $10^{-2} \mathrm{~Pa}$. Then, the quartz ampoule was set in the vertical furnace and heated up to $700{ }^{\circ} \mathrm{C}$ for homogenization. The crystal growth was performed from the bottom by moving up the furnace. The moving rate was controlled as the cooling rate of the quartz ampoule was approximately $0.7^{\circ} \mathrm{C} / \mathrm{h}$. The temperature of the bottom of the ampoule was monitored by a thermocouple during the $\mathrm{ZnSnP}_{2}$ crystal growth. The grown $\mathrm{ZnSnP}_{2}$ bulk crystals were cut into wafers with the diameter of $\sim 8 \mathrm{~mm}$ and the thickness of $0.5 \mathrm{~mm}$. The surface of the wafer was mechanically polished with emery papers and finally $1 \mathrm{~mm}$ diamond slurry on a buff sheet.

The obtained crystals were evaluated by photoluminescence (PL) and time-resolved photoluminescence (TRPL) at room temperature using the measurement system of 
luminescence lifetime (Hamamatsu Photonics, C12132). The wavelength and the power of the excitation laser were $532 \mathrm{~nm}$ and $1.87 \mathrm{~mW}$, respectively, and the beam area was $1.02 \mathrm{~mm}^{2}$. We adopted the structure of $\mathrm{Al} / \mathrm{Al}$-doped $\mathrm{ZnO}(\mathrm{AZO}) / \mathrm{ZnO} / \mathrm{CdS} / \mathrm{ZnSnP} / \mathrm{Mo}$ for the fabrication of solar cells, which is similar to that of CIGS solar cells. ${ }^{[22]}$ First of all, Mo back electrode was deposited with the thickness of approximately $800 \mathrm{~nm}$ by direct current (DC) sputtering on the polished surface of $\mathrm{ZnSnP}_{2}$ wafers. Then, $\mathrm{CdS}$ buffer layer with the thickness of approximately $50 \mathrm{~nm}$, which is widely used as buffer layer of CIGS based solar cells with a conversion efficiency of above $20 \%,{ }^{[22]}$ was prepared on the opposite surface to Mo electrode by chemical bath deposition (CBD) method, where the solution composed of $\mathrm{CdSO}_{4}(1.1 \mathrm{mmol} / \mathrm{L})$, ammonia $(2.3 \mathrm{mmol} / \mathrm{L})$ and thiourea $(56$ $\mathrm{mmol} / \mathrm{L}$ ) was used. The temperature and the deposition time were $80{ }^{\circ} \mathrm{C}$ and $11 \mathrm{~min}$, respectively. Subsequently, $\mathrm{ZnO}$ and $\mathrm{AZO}$ films were formed by radio frequency (RF) magnetron sputtering at room temperature with the thicknesses of 50 and $300 \mathrm{~nm}$, respectively. For the fabrication of $\mathrm{ZnO}$ and $\mathrm{AZO}$ films, $\mathrm{ZnO}$ (99.99\%, Furuuchi Chemical) and $\mathrm{ZnO}-2$ wt. $\% \mathrm{Al}_{2} \mathrm{O}_{3}(99.99 \%$, Furuuchi Chemical) were used as target 
materials. Finally, Al electrode with a grid pattern was fabricated by electron-beam evaporation. The current density-voltage $(J-V)$ characteristics and the external quantum efficiency (EQE) of the solar cells were investigated under the illumination conditions of $100 \mathrm{~mW} / \mathrm{cm}^{2}$ and AM $1.5 \mathrm{G}$ using the measurement system with solar simulator (Bunkoukeiki, CEP-25RR).

\section{Results and discussion}

Figure 1 shows the PL spectrum of a $\mathrm{ZnSnP}_{2}$ bulk crystal evaluated at room temperature, which indicates that the PL peak position is observed at the photon energy of approximately $1.67 \mathrm{eV}$. This value is well consistent with the bandgap of $\mathrm{ZnSnP}_{2}$ with a chalcopyrite structure as reported in the previous works. ${ }^{[14-17]}$ Therefore, it is considered that the peak of PL spectrum shows a band to band transition in the $\mathrm{ZnSnP}_{2}$ bulk crystals.

However, the spectrum is broad especially in lower photon energy region. This might be attributed to damage layer at the surface of crystals or defects such as antisite atoms, which make narrower bandgap due to low degree of order. ${ }^{[23]}$ Subsequently, TRPL 
measurements were performed at the photon energy of $1.67 \mathrm{eV}$. TRPL lifetimes were thus

evaluated by the following function as shown in Fig. 2,

$$
I(t)=A_{1} \exp \left(-t / \tau_{1}\right)+A_{2} \exp \left(-t / \tau_{2}\right),
$$

where $t$ is the time after the laser excitation, $I(t)$ is the luminescence intensity at $t, \tau_{1}$ and $\tau_{2}$ are the fast and slow components of TRPL lifetimes, $A_{1}$ and $A_{2}$ are the pre-exponential factors, respectively. The fast and slow components of TRPL lifetimes, $\tau_{1}$ and $\tau_{2}$, were evaluated to be $\sim 0.44$ and $\sim 14 \mathrm{~ns}$, respectively, from the gradient of the lines in the figure. Chantana et al. reported that the lifetimes of CIGS thin films, which leads to the conversion efficiency of $16.22 \%$, were $\sim 1$ and $\sim 10$ ns for $\tau_{1}$ and $\tau_{2}$, respectively. ${ }^{[24]}$ The measurements for the CIGS films and $\mathrm{ZnSnP}_{2}$ crystals were carried out using the same instrument. It is thus understood that the lifetime of $\mathrm{ZnSnP}_{2}$ is close to that of CIGS. In late years, candidates for solar absorbing materials have been investigated using the TRPL measurement and the importance of a high TRPL lifetime is discussed ${ }^{[25-28]}$ Hence, it is considered that $\mathrm{ZnSnP}_{2}$ is one of promising candidates from the viewpoint of carrier lifetime. 
Solar cell with a structure of an $\mathrm{Al} / \mathrm{AZO} / \mathrm{ZnO} / \mathrm{CdS} / \mathrm{ZnSnP} / \mathrm{Mo}$ was fabricated and its

performance was investigated. Figures 3 and 4 exhibit the $J-V$ characteristics and the EQE spectrum of the corresponding solar cell. The cell parameters are also shown in Fig.

3. We can significantly observe the photocurrent, and the wavelength of the absorption edge is evaluated to be approximately $1.64 \mathrm{eV}$, which is basically consistent with the PL spectrum shown in Fig.1 and the reported bandgap of $\mathrm{ZnSnP}_{2} \cdot{ }^{[14-17]} \mathrm{We}$ here give the first report on the solar cells with a certain absorber of $\mathrm{ZnSnP}_{2}$.

However, the cell performance is still low for a practical use; the conversion efficiency is $\sim 0.09 \%$. The mature device structure is usually adopted for solar cells using novel absorbers at the first step, and then its problems should be investigated and improved to achieve higher efficiency. ${ }^{[29,30]} \mathrm{In} \mathrm{ZnSnP}_{2}$ solar cells, the series resistance was roughly evaluated to be $100 \Omega \mathrm{cm}^{2}$ from the forward bias $J-V$ characteristics, which might lead to the small value of the short circuit current density, $J_{\mathrm{SC}}$. The resistivity of $\mathrm{ZnSnP} 2$ bulk crystals measured by van der Pauw method is $10-70 \Omega \mathrm{cm}^{[16]}$ and the resistance can be thus calculated to be less than $3.5 \Omega \mathrm{cm}^{2}$ for $\mathrm{ZnSnP}_{2}$ wafers with the thickness of $0.5 \mathrm{~mm}$. 
Hence, the large series resistance comes from resistances at the interfaces of $\mathrm{CdS} / \mathrm{ZnSnP} 2$

and/or $\mathrm{ZnSnP} / \mathrm{Mo}$, and the further investigation is necessary to clarify the effect of interfaces. On the other hand, the small value of the open circuit voltage, $V_{\mathrm{OC}}, 0.175 \mathrm{~V}$, might be attributed to the large conduction band offset (CBO) between $\mathrm{CdS}$ and $\mathrm{ZnSnP}{ }_{2}$, $-1.2 \mathrm{eV},{ }^{[31]}$ which makes a cliff at their interface and limits the value of $V_{\mathrm{OC}}$. In the view point of the conduction band offset, it was suggested that $\mathrm{ZnS}$ and $\operatorname{In}_{2} \mathrm{~S}_{3}$ were suitable materials as a buffer layer. From the spectrum shown in Fig.4, EQE is reduced at round $650 \mathrm{~nm}$. One of the reasons is considered to be the bulk recombination of carries generated in deep region of $\mathrm{ZnSnP}_{2}$ crystals due to narrow depletion layer, but it is unclear. Therefore, this point should be investigated and improved for higher conversion efficiency of $\mathrm{ZnSnP} 2$ solar cells. 


\section{Conclusion}

We demonstrated the performance of solar cells using $\mathrm{ZnSnP}_{2}$ compound semiconductor as an absorber. The PL measurements were carried out and the carrier lifetimes in bulk crystals of $\mathrm{ZnSnP}_{2}$ were 0.44 and 14 ns, which were obtained by analysis using double exponential function in time-resolved photoluminescence. The lifetime of $\mathrm{ZnSnP}_{2}$ is close to that of CIGS, which leads to high conversion efficiency of over $16 \%$.

The solar cell with the structure of an $\mathrm{Al} / \mathrm{AZO} / \mathrm{ZnO} / \mathrm{CdS} / \mathrm{ZnSnP} 2 / \mathrm{Mo}$ was prepared. It is really understood that $\mathrm{ZnSnP}_{2}$ is an absorber in the solar cell in this work from the measurements of $J-V$ characteristics and EQE. However, the performance of the solar cells is quite low and some problems should be improved to achieve higher conversion efficiency. First, the higher series resistance, approximately $100 \Omega \mathrm{cm}^{2}$, should be reduced. The resistance of the absorber $\mathrm{ZnSnP}_{2}$ was calculated to be $3.5 \Omega \mathrm{cm}^{2}$ from the resistivity. Therefore, it is necessary to improve the resistance at the heterointerfaces. On the other hand, low open circuit voltage might be attributed to large $\mathrm{CBO}$ at $\mathrm{CdS} / \mathrm{ZnSnP}_{2}$ interface and appropriate buffer materials should be developed. In addition, relatively low EQE at 
around $650 \mathrm{~nm}$ should be improved for higher current density. As described above, we can understand that $\mathrm{ZnSnP}_{2}$ has a great potential for solar cells with higher efficiency although the present efficiency is low. This work is really a start point for the development of $\mathrm{ZnSnP}_{2}$ solar cells. 


\section{Acknowledgements}

This work was partly supported by the JST PRESTO program, the Elements Science and Technology Project from MEXT, and by JSPS KAKENHI Grant Number 26289279. 


\section{References}

[1] Solar Frontier press release, World Record Thin-Film Solar Cell Efficiency: $22.3 \%$, http://www.solar-frontier.com/eng/news/2015/C051171.html, (accessed June 2016).

[2] First Solar press release, Fist Solar Hits Record 22.1\% Conversion Efficiency for CdTe Solar Cell, http://www.greentechmedia.com/articles/read/First-Solar-Hits-Record-22.1Conversion-Efficiency-For-CdTe-Solar-Cell, (accessed June 2016).

[3] W. Wang, M. T. Winkler, O. Gunawan, T. Gokmen, T. K. Todorov, Y. Zhu, D. B. Mitzi, Adv. Energy Mater. 4, DOI: 10.1002/aenm.201301465 (published online 2013).

[4] M. Nakashima, J. Fujimoto, T. Yamaguchi, and M. Izaki, Appl. Phys. Express 8, $042303(2015)$.

[5] T. Minami, Y. Nishi, and T. Miyata, Appl. Phys. Express 8, 022301 (2015).

[6] P. Sinsermsuksakul, L. Sun, S. W. Lee, H. H. Park, S. B. Kim, C. Yang, and R. G. Gordon, Adv. Energy Mater. 4, 1400496 (2014).

[7] A. Ennaoui and H. Tributsch, Solar Cells 13, 197 (1984).

[8] M. Bhushan and A. Catalano, Appl. Phys. Lett. 38, 39 (1981).

[9] A. A. Vaipolin, N. A. Goryunova, L. I. Kleshohinskii, G. V. Loshakova, and E. O. Osmanov, Phys. Status Solidi 29, 435 (1968).

[10] M. Rubenstein and R. W. Ure, J. Phys. Chem. Solids 29, 551 (1968).

[11] N. A. Goryunova, F. P. Kesamanly, and G. V. Loshakova, Sov. Phys. Semicond. 1, 844 (1968).

[12] F. M. Berkovskii, D. Z. Garbuzov, N. A. Goryunova, G. V. Loshakova, S. M. Ryvkin, and G. P. Shpen'kov, Sov. Phys. Semicond. 2, 618 (1968).

[13] N. A. Goryunova, M. L. Belle, L. B. Zlatkin, G. V. Loshakova, A. S. Poplavnoi, and V. A. Chaldyshev, Sov. Phys. Semicond. 2, 1126 (1969). 
[14] A. A. Abdurakhimov, L. V. Kradinova, Z. A. Parimbekov, and Y. V. Rud', Sov. Phys. Semicond. 16, 156 (1982).

[15] M. A. Ryan, M. W. Peterson, D. L. Williamson, J. S. Frey, G. E. Maciel, and B. A. Parkinson, J. Mater. Res. 2, 528 (1987).

[16] S. Nakatsuka, H. Nakamoto, Y. Nose, T. Uda, and Y. Shirai, Phys. Status Solidi C 12, $520(2015)$.

[17] D. O. Scanlon and A. Walsh, Appl. Phys. Lett. 100, 251911 (2012).

[18] W. Shockley and H. J. Queisser, J. Appl. Phys. 32, 510 (1961).

[19] T. Yokoyama, F. Oba, A. Seko, H. Hayashi, Y. Nose, and I. Tanaka, Appl. Phys. Express 6, 061201 (2013).

[20] H. Y. Shin and P. K. Ajmera, Mater. Lett. 5, 211 (1987).

[21] S. Minoura, K. Kodera, T. Maekawa, K. Miyazaki, S. Niki, and H. Fujiwara, J. Appl. Phys. 113, 063505 (2013).

[22] P. Jackson, D. Hariskos, R. Wuerz, O. Kiowski, A. Bauer, T. M. Friedlmeier, and M. Powalla, Phys. Status Solidi RRL 9, 28 (2015).

[23] S. Nakatsuka, Y. Nose, and Y. shirai, in: Photovoltaic Specialist Conference (PVSC), 2015 IEEE 42 nd, New Orleans, United States of America, 2015, (IEEE, 2015) DOI: 10.1109/PVSC.2015.7356089.

[24] J. Chantana, D. Hironiwa, T. Watanabe, S. Teraji, K. Kawamura, and T. Minemoto, Sol. Energy Mater. Sol. Cells 130, 567 (2014).

[25] V. Steinmann, R. E. Brandt, and T. Buonassisi, Nat. Photonics 9, 355 (2015). [26] R. L. Z. Hoye, R. E. Brandt, A. Osherov, V. Stevanović, S. D. Stranks, M. W. B. Wilson, H. Kim, A. J. Akey, J. D. Perkins, R. C. Kurchin, J. R. Poindexter, E. N. Wang, M. G. Bawendi, V. Bulović, and T. Buonassisi, Chem. Eur. J. 22, 2605 (2016). 
[27] R. E. Brandt, R. C. Kurchin, R. L. Z. Hoye, J. R. Poindexter, M. W. B. Wilson, S. Sulekar, F. Lenahan, P. X. T. Yen, V. Stevanović, J. C. Nino, M. G. Bawendi, and T. Buonassisi, J. Phys. Chem. Lett. 6, 4297 (2015).

[28] R. E. Brandt, V. Stevanović, D. S. Ginley, and T. Buonassisi, MRS Commun. 5, 265 (2015).

[29] V. Steinmann, R. Jaramillo, K. Hartman, R. Chakraborty, R. E. Brandt, J. R. Poindexter, Y. S. Lee, L. Sun, A. Polizzotti, H. H. Park, R. G. Gordon, and T. Buonassisi, Adv. Mater. 26, 7488 (2014).

[30] S. Siol, T. P. Dhakal, G. S. Gudavalli, P. P. Rajbhandari, C. DeHart, L. L. Baranowski, and A. Zakutayev, ACS Appl. Mater. Interfaces 8, 14004 (2016).

[31] S. Nakatsuka, Y. Nose, and Y. Shirai, J. Appl. Phys. 119, 193107 (2016). 


\section{Figure captions}

Figure 1 PL spectrum of $\mathrm{ZnSnP}_{2}$ bulk crystal at room temperature. For the measurement, an excitation laser with the wavelength of $532 \mathrm{~nm}$ was used. The laser power and the beam area were set at $1.87 \mathrm{~mW}$ and $1.02 \mathrm{~mm}^{2}$, respectively.

Figure 2 TRPL decay curve of $\mathrm{ZnSnP}_{2}$ bulk crystal at room temperature. The decay curve was measured at the photon energy of $1.67 \mathrm{eV}$. The lifetime was evaluated by the double exponential function: $I(t)=A_{1} \exp \left(-t / \tau_{1}\right)+A_{2} \exp \left(-t / \tau_{2}\right)$.

Figure $3 J-V$ characteristics of the solar cell with the structure of an $\mathrm{Al} / \mathrm{AZO} / \mathrm{ZnO} / \mathrm{CdS} / \mathrm{ZnSnP}_{2} / \mathrm{Mo}$. The characteristics were measured with and without the illumination of AM $1.5 \mathrm{G}$.

Figure 4 EQE spectrum of the solar cell with the structure of an $\mathrm{Al} / \mathrm{AZO} / \mathrm{ZnO} / \mathrm{CdS} / \mathrm{ZnSnP}_{2} / \mathrm{Mo}$. 


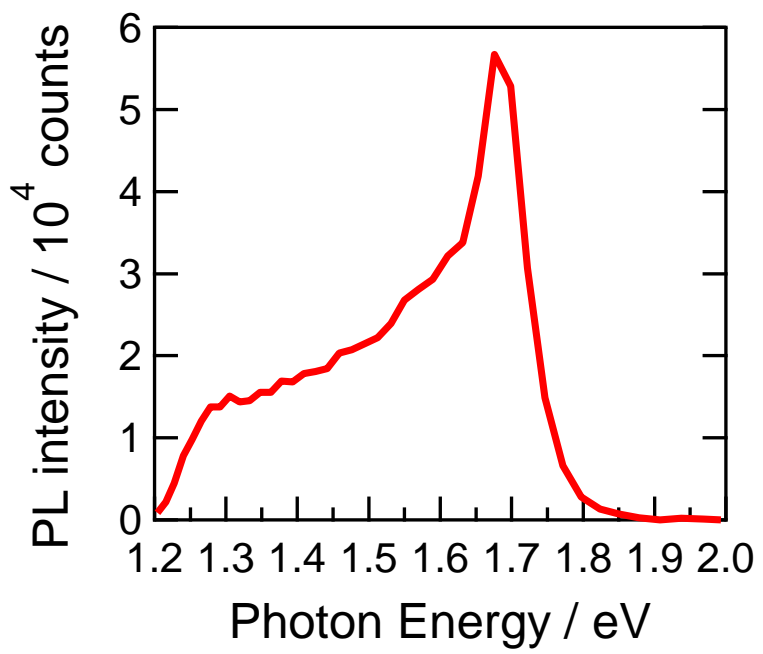

Figure 1 PL spectrum of $\mathrm{ZnSnP}_{2}$ bulk crystal at room temperature. For the measurement, an excitation laser with the wavelength of $532 \mathrm{~nm}$ was used. The laser power and the beam area were set at $1.87 \mathrm{~mW}$ and $1.02 \mathrm{~mm}^{2}$, respectively. 


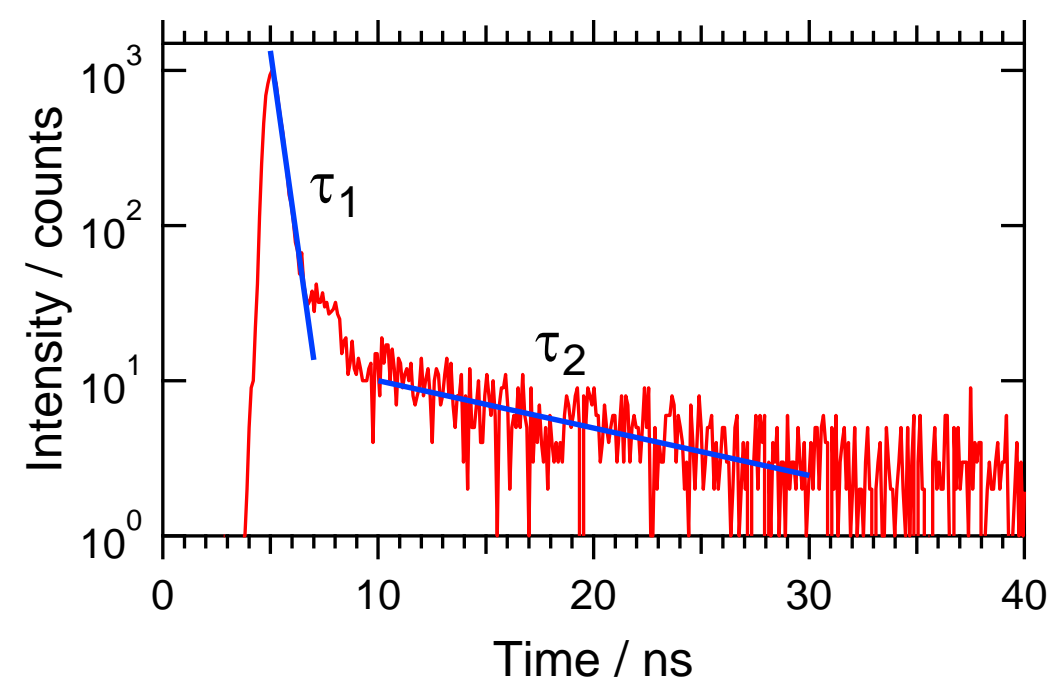

Figure 2 TRPL decay curve of $\mathrm{ZnSnP}_{2}$ bulk crystal at room temperature. The decay curve was measured at the photon energy of $1.67 \mathrm{eV}$. The lifetime was evaluated by the double exponential function: $I(t)=A_{1} \exp \left(-t / \tau_{1}\right)+A_{2} \exp \left(-t / \tau_{2}\right)$. 


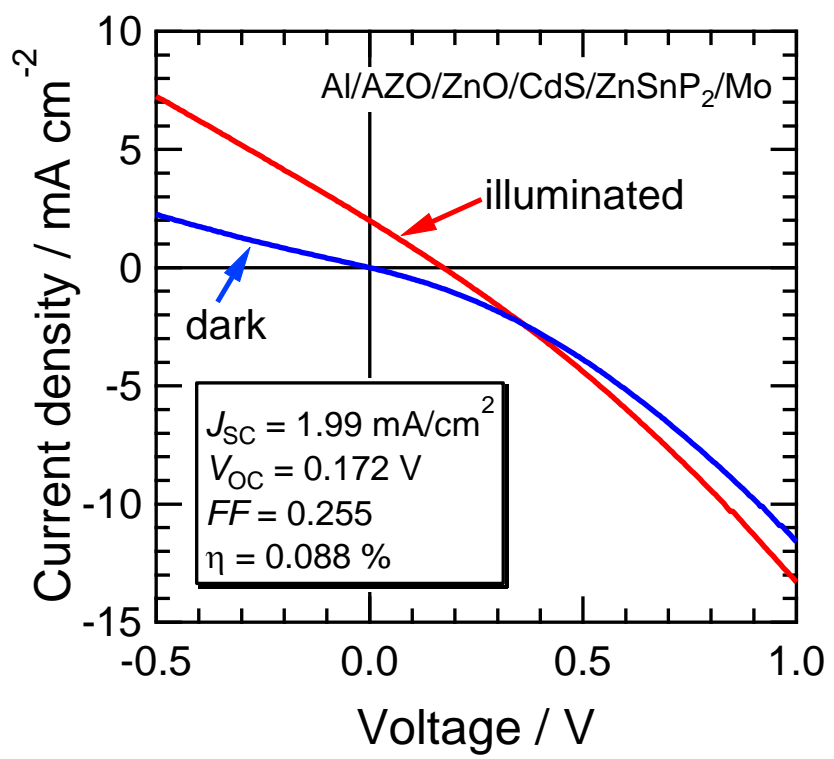

Figure $3 J-V$ characteristics of the solar cell with the structure of an $\mathrm{Al} / \mathrm{AZO} / \mathrm{ZnO} / \mathrm{CdS} / \mathrm{ZnSnP}_{2} / \mathrm{Mo}$. The characteristics were measured with and without the illumination of AM $1.5 \mathrm{G}$. 


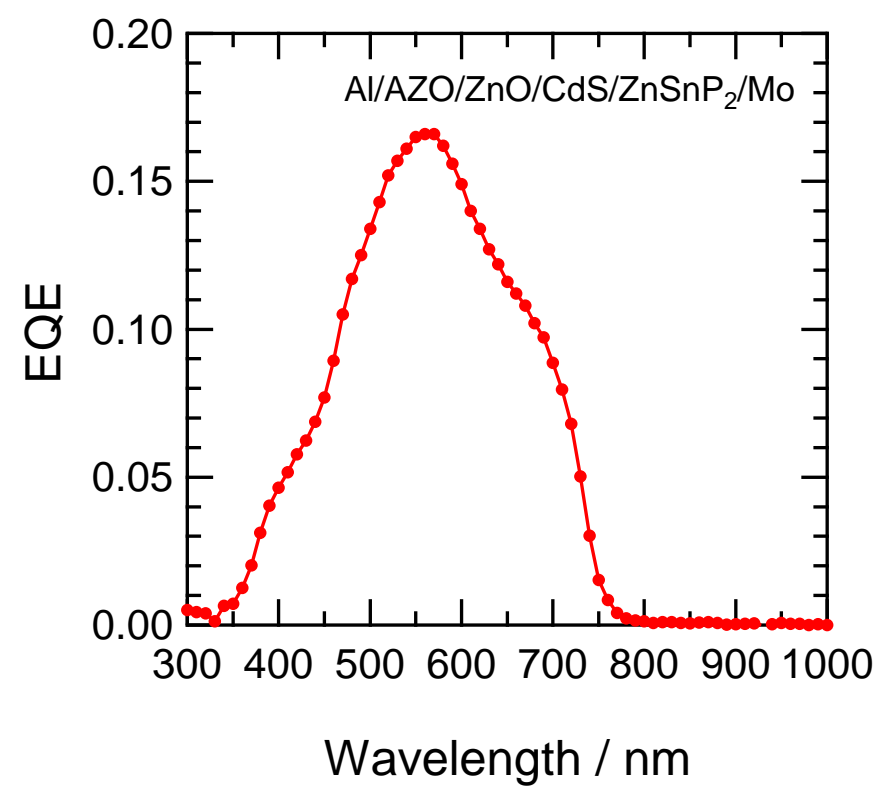

Figure 4 EQE spectrum of the solar cell with the structure of an $\mathrm{Al} / \mathrm{AZO} / \mathrm{ZnO} / \mathrm{CdS} / \mathrm{ZnSnP}_{2} / \mathrm{Mo}$. 